\title{
Connecting Online Work and Online Education at Scale
}

\section{Conference Paper · January 2016}

DOI: $10.1145 / 2851581.2856488$

\section{CITATIONS}

0

6 authors, including:
Joseph Jay Williams

Harvard University

39 PUBLICATIONS 245 CITATIONS

SEE PROFILE
READS

18

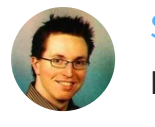

Simon James Caton

National College of Ireland

50 PUBLICATIONS 290 CITATIONS

SEE PROFILE

Some of the authors of this publication are also working on these related projects: 


\section{Connecting Online Work and Online Education at Scale}

\author{
Markus Krause \\ ICSI at, UCBerkeley \\ Berkeley, CA 94704, USA \\ markus@icsi.berkeley.edu
}

\section{Margeret Hall}

Karlsruhe Service Research

Institute

76131 Karlsruhe, Germany

hall@kit.edu

\section{Joseph Jay Williams}

Harvard University

Cambridge, MA, USA

joseph_jay_williams@harvard.edu

\author{
Praveen Paritosh \\ Google, Inc. \\ San Francisco, CA 94105, USA \\ pkp@google.com
}

John Prpić

Lulea University of Technology

97187 Luleå, Sweden

john.prpic@ltu.se

\section{Simon Caton}

National College of Ireland

Dublin, Ireland

simon.caton@ncirl.ie

Permission to make digital or hard copies of part or all of this work for personal or classroom use is granted without fee provided that copies are not made or distributed for profit or commercial advantage and that copies bear this notice and the full citation on the first page. Copyrights for third-party components of this work must be honored. For all other uses, contact the Owner/Author.

Copyright is held by the owner/author(s).

CHI'16 Extended Abstracts, May 07-12, 2016, San Jose, CA, USA

ACM 978-1-4503-4082-3/16/05.

http://dx.doi.org/10.1145/2851581.2856488

\begin{abstract}
Education is one of the eight Millennium Development Goals (MDG) of the United Nations. Considerable interest has been displayed in online education at scale, a new arising concept to realize this goal. Yet connecting online education to real jobs is still a challenge. This $\mathrm{CHI}$ workshop bridges this gap by bringing together groups and insights from related work at HCOMP, CSCW, and Learning at Scale. The workshop aims at providing opportunities for groups not yet in the focus of online education, exemplified by students who have not have equal access to higher education, compared to typical students in MOOCs.
\end{abstract}

The focus is on theoretical and empirical connections between online education and job opportunities which can reduce the financial gap, by providing students with an income during their studies. The workshop explores the technological analogue of the concept of 'apprenticeship', long established in the European Union, and education research [2]. This allows students to do useful work as an apprentice during their studies.

This workshop tackles such questions by bringing together participants from industry (e.g., platforms similar to Upwork, Amazon Mechanical Turk); 
education, psychology, and MOOCs (e.g., attendees of AERA, EDM, AIED, Learning at Scale); crowdsourcing and collaborative work (e.g., attendees of CHI, CSCW, NIPS, AAAI's HCOMP).

\section{Author Keywords}

online education; crowd work; crowdsourcing; MOOCs; apprenticeship

\section{ACM Classification Keywords}

H.5.m. Information interfaces and presentation (e.g., $\mathrm{HCI}$ ): Miscellaneous;

\section{Background}

Due to the success of and our experience during related workshops with more niche communities (HCOMP CSCW, Learning at Scale) we are positive that the topic is ready to be presented to a broader audience. We consider $\mathrm{CHI}$ the perfect venue for our workshop to reach an interested and broad audience on this topic.

The Millennium Development Goals (MGD) Report of 2015 states that primary education is almost universally available in the year 2015. Currently 57 million children worldwide lack access to primary education with a tendency towards zero within the next 20 years. The literacy rate among youth aged 15 to 24 has increased globally from 83 percent to 91 percent between 1990 and 2015. Furthermore, the Internet penetration has grown from 6 per cent of the world's population in 2000 to 43 per cent in 2015 with the number of mobile-cellular subscriptions growing from 738 million in 2000 to over 7 billion in 2015. As a result, 3.2 billion people are linked to a global network of content and applications.
This means that 3.2 billion people currently have access to online education, and that this figure is rising. Although Massively Open Online Courses (MOOCs) are broadly available, they fall short of reaching those students that would benefit most (e.g., underserved populations). Statistics show that the majority of registered learners are already highly educated (Bachelor degree and above) and mostly from developed countries [3]. The reasons for this are manifold. Yet the biggest obstacle for students is that they do not have the time to invest in the learning materials and environment [3]. One reason for those learners to drop out of a course is that their monetary independence is limited. They only have a small amount of time to dedicate to a course besides the necessity of earning a living. This underlying problem not only exists in the developing world. Students in rural areas of the US and Europe as well as traditionally mobile populations (i.e., Roma in Europe) also lack access to higher education and jobs related to these qualifications.

WorkLearn aims at shedding light on the question how to support online students and develop their skills using the plethora of online education while providing them with basic monetary independence to pursue their studies. We are confident that this is an interesting perspective for $\mathrm{CHI}$. Dontcheva at el. investigated how workers gain new skills through interactive tutorials improving photos submitted by requesters [4].

We will investigate the question how to connect online education to jobs. As a starting point of our discussion we will look at a long established method in various European countries, apprenticeships. Creating such opportunities requires connecting students to (online) 
jobs that are related to their field of study and respective skill level. The apprenticeship reinforces and enhances the course-based learning. The recent development of expert labor markets such as Upwork and witmart show that the potential of distributed high skill work is possible and on the rise. Both platforms self-report to be a 1 Billion dollar market for high skill online work ranging from text translation, legal advice, through to solving highly specialized engineering challenges.

Providing opportunities to learn is however only the first step to empower students to take charge of their future. As most benefiting students live in rural areas where no jobs with a high education profile are available the question remains how these students will find a job after their studies. To tackle this challenge we will examine the use case of school-based assignments. In the US alone students spend 18 Billion hours a year on assignments. These assignments are mostly read by a single teacher.

This is similar to assignments in online education either graded by peers, computers, or teachers yet also disappearing without leaving a graspable trace. We plan to discuss opportunities to use assignments in online education for different purposes as a portfolio, part of the apprenticeship, and to extract resumes from the collected data. Such a resume or portfolio might provide actual motivational benefit for students [5], as their work immediately turns into observable changes and even monetary gain.

This vision is connected to a variety of multidisciplinary challenges. Although, the vision overarches many fields, the resulting research questions that can be operationalized are concrete. The concrete aspects WorkLearn will address include:

- How to optimally administer exams and ensure diligence of work in learning at scale scenarios

- How to estimate assignment quality in courses with thousands of students;

Other questions are specific to the endeavor of providing assignments that are as well paid labor, e.g.

- How to predict if a student is ready to take a certain real world task; and

- What are the requirements of turning the results of such tasks into meaningful resumes?

- What are the business model requirements for apprenticeships connected to online education?

The workshop aims to discuss and evolve concrete research questions, possible solutions, and to establish an international group of researches collaborating on this topic. Given the success of the prior installments of this workshop we hope to attract former participants as well as open it up to others active in the $\mathrm{CHI}$ community such as Kenneth R. Koedinger, Michael Bernstein, Lena Mamykina, Severin Hacker, Jeffrey P. Bigham, Steven P. Dow, and Björn Hartmann.

\section{Organizers}

Markus Krause is a visiting scholar at the UC Berkeley. In his research, he investigates the intersection between online work and learning at scale. $\mathrm{He}$ is involved in projects exploring self-directed, selforganized, and personalized online education at scale $[8,9,13]$. He also worked as a professional game designer and art-director in the gaming industry. Part 
of his research investigates learning as a core element of play [7].

Margeret Hall is a Post-Doctoral researcher and the research lead of the group 'Participative and

Collaborative Services' at the Institute for Information Systems and Marketing at the Karlsruhe Institute of Technology. She previously held roles in civil society and public education, including with the United Nations. Her research concentrates on the interdisciplinary investigation and designing of participatory, crowdbased mechanisms. She focuses on disentangling and understanding participant behavior and social media's facilitation of broad-scale participation $[1,10]$

Joseph Jay Williams, Harvard University, USA: Joseph is a Research Fellow at HarvardX. He carries out experimental and computational cognitive science research on online learning and "MOOClets". He has organized a workshop on online learning at CHI 2014 [11], HCOMP 2014 [6], and CSCW 2015 [12], as well as online education symposia at the the American Education Research Association, Cognitive Science Society, and the Association for Psychological Science.

Simon Caton is a Lecturer of Data Analytics at the National College of Ireland. His research focuses on the analytics and understanding of online social

communities as well as the computational architectures to support such studies. In 2013, he organized the third IEEE International Conference on Social Computing and Its Applications.

Praveen Paritosh, Google, USA: Praveen is a research scientist at Google, working on human and machine intelligence. With Matt Lease and Tatiana Josephy, he organized a successful workshop at HCOMP 2013, Crowdsourcing at Scale (www.crowdscale.org), and is on the organizing and program committees of AAAI. Praveen will be helping with planning and keeping track of the agenda, breakout sessions, and group mailing lists and communications.

John Prpić is a PhD Candidate in the Faculty of Business Administration, Technology and Social Sciences at Lulea University of Technology in Sweden. John's research focuses on the organizational use of ITmediated crowds in private and public sector settings, for the purposes of innovation, education, policy, public health, governance, and collective intelligence. He is Co-Chair of the "Crowd Science \& the Organizational use of IT-mediated Crowds" mini-track at HICSS.

\section{Website}

We will update the existing website for the previous workshops: http://www.worklearn.org/. The website as is provides information on the 2014 Workshop [6].

\section{Pre-workshop Plans}

Due to our good experience in previous workshops we plan to operation on an invitation-only basis. Preworkshop activities include the identification and solicitation of birds of a feather authors and papers. However, we also want to be inviting to younger researches. Therefore, we will also create a latebreaking deadline for broader community submissions. Birds of a feather papers may submit 2-4 pages. Late breaking submissions should submit 2 page position papers. To appeal to the broader audience of $\mathrm{CHI}$ we also plan to disseminate information about the workshop via mailing lists and other appropriate venues, in addition to advertising on the website. An 
overarching goal of WorkLearn is to establish a group of research's and to strengthen trans-Atlantic collaboration. Considerable preparation will be undertaken for this, including at least one plenary meeting before $\mathrm{CHI}$ in San Jose. Additionally, we plan to recruit subject experts in the lead up to the conference. We have made excellent experience in the past inviting a group of distinguished guest speakers to start discussions on specific topics. This is reflected in the proposed schedule.

\section{Workshop Structure}

WorkLearn is a one-day event focusing on community building and exchange, broken into three sections. The opening section facilitates this with short introductions and keynotes in the morning. WorkLearn participants are invited to present their position papers as one-slide, 1-3 minute talks. Subgroups are then formed to collaboratively develop aims and foci points of a white paper and preparing concrete collaborations for the majority of the day. The final session re-integrates the group for braiding together the contributions of the day, and the discussion of next steps. An optional social event will follow for all participants. Necessary for success are standard presentation materials (projector, screen) and white boards/writing space along with appropriate writing utensils.

\section{Post-Workshop Plans}

A core goal of the workshop is to facilitate the formal establishment of a research community. Here, working groups will formed at the workshop to lay out a roadmap of future research and collaborative actions; forming initial engagement from workshop participants, as well as acting as an anchor for future collaborators to link to and join the working groups. Subsequently, we will explore options to accrue funding opportunities to facilitate a networking instrument for researchers to cooperate and coordinate funded research activities; where the EU COST network is one such example.

\section{Call for Participation}

WorkLearn 2014 is a full-day workshop at CHI 2016 that will investigate the question wow to link online education and work at scale. We will investigate concepts like online apprenticeship and how to provide monetary independence for students in online education. We aim to establish a cross Atlantic community interested in the question how online learning can provide education for people with a low socioeconomic status. Authors should submit 2-4 page position papers. Submissions will be accepted via email and reviewed by the workshop organizers. Submissions are chosen based on relevance, quality, and contribution. Authors will be notified on 21 December, 2015.

\section{References}

1. Benedikt Boecking, Margeret Hall, and Jeff Schneider. 2015. Event Prediction With Learning Algorithms-A Study of Events Surrounding the Egyptian Revolution of 2011 on the Basis of Micro Blog Data. Policy \& Internet: n/a-n/a. http://doi.org/10.1002/poi3.89

2. Allan Collins, J Brown, and S. Newman. 1987. Cognitive apprenticeship: Teaching the craft of reading, writing and mathematics. Palo Alto, CA, USA.

3. Edward Cutrell, Jacki O'Neill, Srinath Bala, et al. 2015. Blended Learning in Indian Colleges with Massively Empowered Classroom. Proceedings of the Second (2015) ACM Conference on Learning @ 
Scale - L@S '15, ACM Press, 47-56. http://doi.org/10.1145/2724660.2724666

4. Mira Dontcheva, Robert R. Morris, Joel R. Brandt, and Elizabeth M. Gerber. 2014. Combining crowdsourcing and learning to improve engagement and performance. Proceedings of the 32nd annual ACM conference on Human factors in computing systems - CHI '14, ACM Press, 3379-3388. http://doi.org/10.1145/2556288.2557217

5. Reinaldo Fernandez. 2014. A Cognitive Apprenticeship Approach for Teaching Abstract and Complex Skills in an Online Learning Environment.

6. Tatiana Josephy, Matt Lease, Praveen Paritosh, et al. 2014. Workshops Held at the First AAAI Conference on Human Computation and

Crowdsourcing: A Report. AI Magazine 35, 2: 7578.

7. Markus Krause, Marc Mogalle, Henning Pohl, and Joseph Jay Williams. 2015. A Playful Game Changer: Fostering Student Retention in Online Education with Social Gamification In review Do not cite or circulate. L@S'15 Proceedings of the second ACM conference on Learning@ scale conference, ACM Press.

8. Markus Krause. 2014. A behavioral biometrics based authentication method for MOOC's that is robust against imitation attempts. Proceedings of the first ACM conference on Learning @ scale conference - L@S '14, ACM Press, 201-202. http://doi.org/10.1145/2556325.2567881

9. Markus Krause. 2015. Stylometry-based Fraud and Plagiarism Detection for Learning at Scale. Proceeding of the KSS Workshop'15.

10. Andreas Lindner, Margeret Hall, Claudia Niemeyer, and Simon Caton. 2015. BeWell. Proceedings of the 33rd Annual ACM Conference Extended Abstracts on Human Factors in Computing Systems - CHI EA '15, ACM Press, 1055-1060.

http://doi.org/10.1145/2702613.2732787
11. Joseph Jay Williams, René F. Kizilcec, Daniel M. Russell, and Scott R. Klemmer. 2014. Learning innovation at scale. Proceedings of the extended abstracts of the 32nd annual ACM conference on Human factors in computing systems - CHI EA'14, ACM Press, 131-134.

http://doi.org/10.1145/2559206.2559234

12. Joseph Jay Williams, Markus Krause, Praveen Paritosh, et al. 2015. Connecting Collaborative \& Crowd Work with Online Education. Proceedings of the 18th ACM Conference Companion on Computer Supported Cooperative Work \& Social Computing 313-318.

13. Alvin Yuan, Kurt Luther, Markus Krause, Sophie Vennix, Björn Hartmann, and Steven P. Dow. 2016. Almost an Expert: The Effects of Rubrics and Expertise on Perceived Value of Crowdsourced Design Critiques. The 19th ACM conference on Computer-Supported Cooperative Work and Social Computing (CSCW'16), to appear. 